\title{
Correction: Surgical education in the 21st century: implications for sexual medicine
}

\section{Koenraad van Renterghem · Ahmed Ghazi}

Published online: 14 April 2020

(c) The Author(s), under exclusive licence to Springer Nature Limited 2020

Correction to: International Journal of Impotence Research https://doi.org/10.1038/s41443-019-0218-8

The following text was previously omitted:

'This surgical education program is an ESSM (European Society for Sexual Medicine) initiative designed and developed within the scientific board of ESSM. The certificate that will follow after completing this Surgical Academy will be given by ESSM'. This has now been corrected in both the PDF and HTML versions of the Article. 